\title{
Isolation, structure elucidation and antibacterial activities of streptothricin acids
}

\author{
Zhiqin $\mathrm{Ji}^{1}$, Mingan Wang ${ }^{2}$, Shaopeng $\mathrm{Wei}^{1}$, Jiwen $\mathrm{Zhang}^{1}$ and Wenjun $\mathrm{Wu}^{1}$ \\ Five streptothricin acids (compounds 1-5) were isolated by ion-exchange resin chromatography and preparative RP-HPLC from \\ the fermentation broth of Streptomyces qinlingensis. Their structures were elucidated mainly by analyses of the IR, HR-EIS-MS \\ and NMR spectral data. They were deduced as two known compounds, streptothricin F acid (1) and streptothricin D acid (2), \\ and three new compounds, 12-carbamoylstreptothricin E acid (3), 12-carbamoylstreptothricin D acid (4) and N-acetyl- \\ streptothricin D acid (5), respectively. The antibacterial activities of 1-5 against Escherichia coli, Bacillus subtilis, \\ Staphylococcus aureus, Bacillus cereus and Pseudomonas aeruginosa were assayed by micro-broth dilution. Comparison of the \\ MICs with streptothricin F and D showed that the antimicrobial activities of 1-5 were decreased significantly but varied with \\ the structures.
}

The Journal of Antibiotics (2009) 62, 233-237; doi:10.1038/ja.2009.16; published online 20 March 2009

Keywords: antibacterial activity; streptothricin acid; structural elucidation

Streptothricin antibiotic is a type of broad-spectrum antibiotics. As streptothricin F was isolated from Streptomyces lavendulae in 1942, ${ }^{1}$ dozens of streptothricins (STs) have been isolated from natural resources. Although they were shown to possess strong antimicrobial activity against many species of fungi and bacteria, their application in the therapeutic area has been hampered because of the nephrotoxicity. ${ }^{2-5}$ Hamano et al. ${ }^{6}$ isolated a novel ST-resistance gene (sttH) and showed that the hydrolysis of the amide bond of streptolidine lactam could be catalyzed by the enzyme in vitro. With the breaking of the amide bond, the antimicrobial activity of streptothricin D (ST-D) was altered from broad-spectrum to bacteria-specific, and its toxicity against eukaryotic cells was also reduced at the same time. These results suggest that ST-D acid is a potential candidate for clinical development or use as a new lead compound for drug discovery. Attempts at preparing ST acids were made from STs chemically, but only ST-F acid, which bears one $\beta$-lysine, was readily obtained, whereas others that bear more $\beta$-lysine residues were not prepared successfully. ${ }^{7,8}$ In addition, only the bio-activities of ST-F and ST-D acids have been investigated. ${ }^{6}$

In the process of screening for new antibiotics, S. qinlingensis, a ST producer, was isolated from soil samples. ST-F, ST-D and two other novel compounds, 12-carbamoyl-ST-F and 12-carbamoyl-ST-D, have been isolated from its fermentation broth in our laboratory. ${ }^{9}$ In subsequent research, a facile LC-MS/MS method based on RP-HPLC coupled with electrospray ionization tandem mass spectrometry was used for the analysis of STs in the fermentation broth of S. qinlingensis. ${ }^{10}$ A total of 19 ST-like compounds were identified or tentatively characterized on the basis of their mass spectral data; among them, 12 were ST acids. Here, we report the isolation, structure elucidation and antibacterial activities of five ST acids that were isolated by ion-exchange resin chromatography and preparative RP-HPLC from the fermentation broth of $S$. qinlingensis. These compounds were identified as two known compounds, ST-F acid (1) and ST-D acid (2), and three new compounds, 12-carbamoylstreptothricin E acid (3), 12-carbamoylstreptothricin D acid (4) and N-acetylstreptothricin D acid (5). The antibacterial activities of 1-5 against Escherichia coli, Bacillus subtilis, Staphylococcus aureus, Bacillus cereus and Pseudomonas aeruginosa were assayed by means of micro-broth dilution. The results indicated that $\mathbf{1 - 5}$ exhibited less antibacterial activities when compared with that of ST-D, but the extent of decrease varied with the structures.

\section{RESULTS AND DISCUSSION}

Physicochemical properties of 3-5

Compound 3: colorless amorphous powder, m.p. $132-134{ }^{\circ} \mathrm{C}(\mathrm{dec})$, $[\alpha]_{\mathrm{D}}^{25}-14.0(\mathrm{c} 0.1, \mathrm{MeOH})$. IR $v_{\max } \mathrm{cm}^{-1}: 3382,1651,1555,1492$, 1388, $1070 \mathrm{~cm}^{-1} .{ }^{1} \mathrm{H}$ and ${ }^{13} \mathrm{C}$ NMR: see Tables 1 and 2 . Highresolution electrospray ionization mass spectometry (HR-ESI-MS) $(m / z): 649.3630[\mathrm{M}+\mathrm{H}]^{+}$, calcd for $\mathrm{C}_{25} \mathrm{H}_{49} \mathrm{~N}_{10} \mathrm{O}_{10}, 649.3628$.

Compound 4: colorless amorphous powder, m.p. $150-152^{\circ} \mathrm{C}(\mathrm{dec})$, $[\alpha]_{\mathrm{D}}^{25}+8$ (c 0.1, MeOH). IR $v_{\max } \mathrm{cm}^{-1}: 3396,1655,1558,1492,1390$, $1067 \mathrm{~cm}^{-1} ;{ }^{1} \mathrm{H}$ and ${ }^{13} \mathrm{C}$ NMR: see Tables 1 and 2 . HR-ESI-MS $(\mathrm{m} / z)$ : $777.4576[\mathrm{M}+\mathrm{H}]^{+}$, calcd for $\mathrm{C}_{31} \mathrm{H}_{62} \mathrm{~N}_{12} \mathrm{O}_{11}, 777.4577$.

Compound 5: colorless amorphous powder, m.p. $172-174{ }^{\circ} \mathrm{C}(\mathrm{dec})$, $[\alpha]_{\mathrm{D}}^{25}+4.2(\mathrm{c} 0.1, \mathrm{MeOH})$. IR $v_{\max } \mathrm{cm}^{-1}: 3418,1652,1554,1445,1388$, $1071 \mathrm{~cm}^{-1} ;{ }^{1} \mathrm{H}$ and ${ }^{13} \mathrm{C}$ NMR: see Tables 1 and 2 . HR-ESI-MS $(\mathrm{m} / z)$ : $819.4683[\mathrm{M}+\mathrm{H}]^{+}$, calcd for $\mathrm{C}_{33} \mathrm{H}_{62} \mathrm{~N}_{12} \mathrm{O}_{12}, 819.4683$.

${ }^{1}$ Institute of Pesticide Science, Northwest Agricultural and Forestry University, Shaanxi, China and ${ }^{2}$ Department of Applied Chemistry, China Agricultural University, Beijing, China Correspondence: Professor W Wu, Institute of Pesticide Science, Northwest Agricultural \& Forestry University, Yangling, Shaanxi 712100, China. E-mail: wenjun_wu@263.net

Received 7 January 2009; revised 11 February 2009; accepted 17 February 2009; published online 20 March 2009 
Table $1{ }^{1} \mathrm{H}$ NMR data of compounds $1-5\left(500 \mathrm{MHz}\right.$, in $\left.\mathrm{D}_{2} \mathrm{O}\right)$

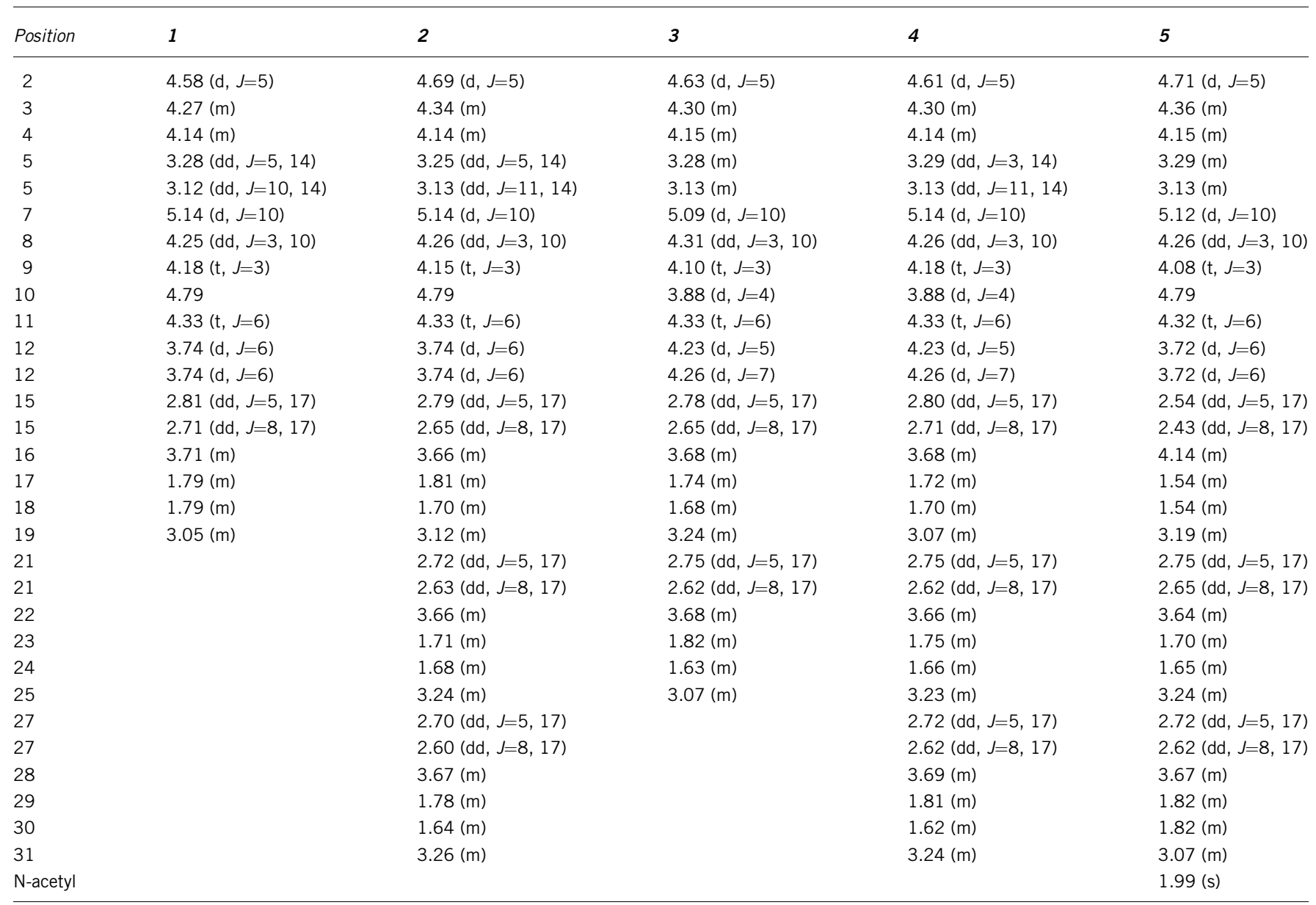

\section{Structure elucidation}

Two known compounds $(\mathbf{1}, \mathbf{2})$ and three novel compounds $(\mathbf{3}-\mathbf{5})$ were obtained from the fermentation broth of $S$. qinlingensis finally. Compounds $\mathbf{1}$ and $\mathbf{2}$ were identified as ST-F acid and ST-D acid on the basis of the M.P., IR, MS and NMR data. ${ }^{7,8}$

Compound 3 was obtained as a colorless amorphous powder. The molecular formula $\mathrm{C}_{25} \mathrm{H}_{48} \mathrm{~N}_{10} \mathrm{O}_{10}$ was determined by HR-ESI-MS at $m / z 649.3630[\mathrm{M}+\mathrm{H}]^{+}$(calcd for $\mathrm{C}_{25} \mathrm{H}_{49} \mathrm{~N}_{10} \mathrm{O}_{10}, 649.3628$ ). The IR spectra showed the characteristic absorption bands at 1654 and $1556 \mathrm{~cm}^{-1}$, which revealed the existence of a peptide bond. The NMR spectral data (Tables 1 and 2) suggested the presence of two amido groups, one carboxylic acid group, one carbamoyl group and one guanidino group. The spectral characteristics were very similar to those of STs. By comparing the ${ }^{1} \mathrm{H}$ and ${ }^{13} \mathrm{C}$ NMR data of 3 with those of ST-D acid (2), we found that the chemical shift of C-4, C-5 in the ${ }^{13} \mathrm{C}$ NMR spectra and the chemical shift of $\mathrm{H}-4$ and $\mathrm{H}-5$ in the ${ }^{1} \mathrm{H}$ NMR spectra were not different. Compound 3 was assumed to be the ST acid type compound. The hypothesis is also proved by the results of ESI-MS/MS; $m / z$ 171, which was assigned to streptolidine, was a characteristic ion peak of STs, whereas the corresponding ion was observed at $m / z 189$ in the spectrum of 3 . This indicated that streptolidine lactam was converted into acid for compound 3 . The differences between the ${ }^{1} \mathrm{H}$ and ${ }^{13} \mathrm{C}$ NMR data of $\mathbf{3}$ and 2 were also observed; we found a chemical shift of C-9 downfield 2.6 p.p.m., C-10 upfield 2.2 p.p.m., C-11 upfield 1.1 p.p.m. and C-12 downfield
3.6 p.p.m. in the ${ }^{13} \mathrm{C}$ NMR spectrum, as well as a chemical shift of H-10 upfield 0.9 p.p.m. and H-12 downfield 0.5 p.p.m. in the ${ }^{1} \mathrm{H}$ NMR spectrum. These differences may be attributed to the variety of the substitution position of the carbamoyl group attached to D-gulosamine in which the substitution position of carbamoyl was transferred from C-10 to C-12. This presumption was confirmed by the heteronuclear multiple-bond correlation (HMBC) experiment. In the HMBC spectra of 2, the protons of $\mathrm{H}-9, \mathrm{H}-10$ and $\mathrm{H}-11$ were correlated with the carbonyl of the carbamoyl group. However, the carbonyl of the carbamoyl group was correlated with the protons of $\mathrm{H}-10, \mathrm{H}-11$ and $\mathrm{H}-12$ in the HMBC spectra of 3. Thus, the carbamoyl group of 3 was substituted at $\mathrm{C}-12$, and the compound was identified as 12-carbamoylstreptothricin E acid. To our best knowledge, only four 12-carbamoylstreptothricins, 12-carbamoylstreptothricin F, D, C and $\mathrm{B}$, have been reported; so compound 3 is a novel 12-carbamoylstreptothricin antibiotic (Figure 1). ${ }^{9,11}$

Compound 4 was obtained as a colorless amorphous powder. The molecular formula $\mathrm{C}_{31} \mathrm{H}_{60} \mathrm{~N}_{12} \mathrm{O}_{11}$ was determined by HR-ESI-MS at $m / z 777.4576[\mathrm{M}+\mathrm{H}]^{+}$(calcd for $\mathrm{C}_{31} \mathrm{H}_{61} \mathrm{~N}_{12} \mathrm{O}_{11}, 777.4577$ ). The IR spectra showed the characteristic absorption bands at 1654 and $1556 \mathrm{~cm}^{-1}$, which revealed the existence of a peptide bond. The NMR spectral data (Tables 1 and 2) suggested the presence of three amido groups, one carboxylic acid group, one carbamoyl group and one guanidino group. By comparing the ${ }^{1} \mathrm{H}$ and ${ }^{13} \mathrm{C}$ NMR data of 4 with those of $\mathbf{2}$ and 3, we found that the chemical shift of C-4, C-5, 
Table $2{ }^{13} \mathrm{C}$ NMR data of compounds $1-5\left(125 \mathrm{MHz}\right.$, in $\left.\mathrm{D}_{2} \mathrm{O}\right)$

\begin{tabular}{|c|c|c|c|c|c|}
\hline Position & 1 & 2 & 3 & 4 & 5 \\
\hline 1 & 173.53 & 173.45 & 172.05 & 174.26 & 173.10 \\
\hline 2 & 56.74 & 56.73 & 57.05 & 57.18 & 56.83 \\
\hline 3 & 61.33 & 61.31 & 61.54 & 61.55 & 61.27 \\
\hline 4 & 67.97 & 67.96 & 67.96 & 67.98 & 67.96 \\
\hline 5 & 40.59 & 40.61 & 40.61 & 40.61 & 41.32 \\
\hline 6 & 158.46 & 157.84 & 158.26 & 158.35 & 158.46 \\
\hline 7 & 79.04 & 79.09 & 79.14 & 79.14 & 79.13 \\
\hline 8 & 48.95 & 48.92 & 48.68 & 48.92 & 48.93 \\
\hline 9 & 66.42 & 66.46 & 69.03 & 67.98 & 66.74 \\
\hline 10 & 69.98 & 69.99 & 67.76 & 67.76 & 69.97 \\
\hline 11 & 73.37 & 73.38 & 72.27 & 72.28 & 73.32 \\
\hline 12 & 60.19 & 60.21 & 63.79 & 63.79 & 60.26 \\
\hline 13 & 157.85 & 158.45 & 158.99 & 158.99 & 157.82 \\
\hline 14 & 171.97 & 172.11 & 171.82 & 172.08 & 173.82 \\
\hline 15 & 36.26 & 36.80 & 36.61 & 36.58 & 41.32 \\
\hline 16 & 48.25 & 48.67 & 48.46 & 48.43 & 47.17 \\
\hline 17 & 28.97 & 29.46 & 29.41 & 29.37 & 31.37 \\
\hline 18 & 22.85 & 24.28 & 24.27 & 24.25 & 24.85 \\
\hline 19 & 38.89 & 38.76 & 38.77 & 38.79 & 38.96 \\
\hline 20 & & 171.82 & 171.62 & 171.62 & 171.62 \\
\hline 21 & & 36.59 & 36.82 & 36.58 & 36.58 \\
\hline 22 & & 48.66 & 48.49 & 48.43 & 48.46 \\
\hline 23 & & 29.38 & 29.07 & 29.06 & 29.42 \\
\hline 24 & & 22.88 & 22.89 & 24.25 & 24.30 \\
\hline 25 & & 38.76 & 38.91 & 38.79 & 36.77 \\
\hline 26 & & 171.61 & & 171.62 & 171.62 \\
\hline 27 & & 36.56 & & 36.58 & 36.85 \\
\hline 28 & & 48.45 & & 48.43 & 48.70 \\
\hline 29 & & 29.06 & & 29.06 & 29.07 \\
\hline 30 & & 22.89 & & 22.90 & 22.90 \\
\hline 31 & & 38.89 & & 38.88 & 39.00 \\
\hline $\mathrm{N}$-acetyl & & & & & $173.10,22.10$ \\
\hline
\end{tabular}

C-10, C-12 in the ${ }^{13} \mathrm{C}$ NMR spectra, and the chemical shift of $\mathrm{H}-4$, $\mathrm{H}-5, \mathrm{H}-10, \mathrm{H}-12$ in the ${ }^{1} \mathrm{H}$ NMR spectra were similar; so 4 also belongs to 12-carbamoylstreptothricin acid. The molecular weight of 4 is $128 \mathrm{Da}$ higher than that of $\mathbf{3}$, which corresponds to a molecule of $\beta$-lysine. On the basis of the ${ }^{1} \mathrm{H}$ and ${ }^{13} \mathrm{C}$ NMR data and $\mathrm{HMBC}$ spectra, 4 was identified as 12-carbamoylstreptothricin D acid.

Compound $\mathbf{5}$ was obtained as a colorless amorphous powder. The molecular formula $\mathrm{C}_{33} \mathrm{H}_{62} \mathrm{~N}_{12} \mathrm{O}_{12}$ was determined by HR-ESI-MS at $m / z$ 819.4683 $[\mathrm{M}+\mathrm{H}]^{+}$(calcd for $\mathrm{C}_{33} \mathrm{H}_{63} \mathrm{~N}_{12} \mathrm{O}_{12}, 819.4683$ ). The IR spectra showed the characteristic absorption bands at 1651 and $1554 \mathrm{~cm}^{-1}$, which revealed the existence of a peptide bond. The NMR spectral data (Tables 1 and 2) suggested the presence of four amido groups, one carboxylic acid group, one carbamoyl group and one guanidino group. By comparing the ${ }^{1} \mathrm{H}$ and ${ }^{13} \mathrm{C}$ NMR data of 5 with those of 2-4, we found that the chemical shift of C-4, C-5 in the ${ }^{13} \mathrm{C}$ NMR spectrum, and $\mathrm{H}-4, \mathrm{H}-5$ in the ${ }^{1} \mathrm{H}$ NMR spectrum were similar to 3; the chemical shift of $\mathrm{C}-10, \mathrm{C}-12$ in the ${ }^{13} \mathrm{C}$ NMR spectrum, and $\mathrm{H}-10, \mathrm{H}-12$ in the ${ }^{1} \mathrm{H}$ NMR spectrum were similar to 2; so 5 belongs to ST acid. The ${ }^{1} \mathrm{H}$ NMR spectrum of 5 showed a singlet $(3 \mathrm{H})$ at $\delta 1.99$ in addition to all the signals observed in that of 2 , and the signal of the methyl group was observed at $\delta 22.10$ in the ${ }^{13} \mathrm{C}$ NMR spectrum of $\mathbf{5}$. In the HMBC spectrum of $\mathbf{5}$, we could find that the methyl group is attached to a carbon $(\delta 173.10)$ of carbonyl group, which was absent in the ${ }^{13} \mathrm{C}$ NMR spectrum of 2 . The protons of $\mathrm{H}-15$ and $\mathrm{H}-16$ were correlated with the carbonyl group at $\delta 173.10$, indicating that the acetyl group was attached to the amino group of $\mathrm{C}-16$. Thus, 5 was identified as $\mathrm{N}$-acetylstreptothricin D acid.

Streptothricin F acid is the most investigated compound of ST acids, and was first prepared from ST-F by partial hydrolysis, whereas the other ST acids bearing more $\beta$-lysine residues were not readily obtained chemically. ${ }^{7,8}$ The results may be attributed to that, although STs possess easily hydrolyzable bonds, such as ester and amido bonds, but the hydrolysis is strongly influenced by the number of $\beta$-lysine. In 2006, Hamano et al. ${ }^{6}$ isolated a novel ST-resistance gene (sttH) from S. albulus, which could catalyze the transformation of ST-D and ST-F from lactam to acid in vitro. The results of HPLC-MS/MS analysis also indicated the distribution of ST acids in the metabolites of $S$. qinlingensis. We therefore hypothesized that a similar resistance gene may exist in this actinomycete, the research of which is under way in our laboratory.

\section{Antibacterial assay}

Antimicrobial activities of compounds 1-5 against B. subtilis, $S$. aureus, E. coli, B. cereus and P. aeruginosa were determined by the micro-broth dilution method, and the results are showed in Table 3. In a comparison of the MICs of STs F and D with those of $\mathbf{1 - 5}$, the antimicrobial activities of $\mathbf{1 - 5}$ were decreased significantly, but the extents varied with the structures. The structural activity relationship of STs has been described in previous research, but that of ST acids was not investigated thoroughly. ${ }^{12-15}$ To our best knowledge, only the antibacterial activities of ST acids $\mathrm{F}$ and $\mathrm{D}$ were reported up to now. ST-D acid exhibited higher activity against B. subtilis and S. aureus than did ST-F acid, and this indicates that the number of $\beta$-lysine plays an important role in the antibacterial activity for this type of ST acid antibiotics. The activity of $\mathbf{4}$ was slightly lower than that of $\mathbf{2}$, and the only difference between them is the substituted position of the carbamoyl group in the D-gulosamine moiety, which implies that their activities were also influenced by the substituted position of the carbamoyl group. It is noticeable that acetylation of $\beta$-lysine almost resulted in the loss of activity, and this phenomenon was identical with that of classical ST antibiotics. ${ }^{12,13}$

\section{METHODS}

\section{Microorganism and fermentation}

The producing strain S. qinlingensis was isolated from a soil sample collected in Qinling Mountain, Shannxi Province, China, and identified by its morphology, physiology, biochemistry and $16 \mathrm{~S}$ rRNA gene sequence. The voucher specimen of this streptomycete was deposited at the China General Microbiological Culture Collection Center as CGMCC1381, and the 16S rDNA sequence was registered in GenBank with the accession no: AM167521 in the National Center for Biological Information.

The spores of $S$. qinlingensis grown on Gause's No. 1 agar were used to inoculate into a $250 \mathrm{ml}$ flask containing $50 \mathrm{ml}$ of a sterile seed medium consisting of glucose $0.8 \%$, soluble starch $0.8 \%$, beef extract $0.6 \%$, peptone $1.0 \%$, and $\mathrm{NaCl} 0.5 \%, \mathrm{pH} 7.2$. The flask was shaken on a shaker at 210 r.p.m. for $24 \mathrm{~h}$ at $28^{\circ} \mathrm{C}$. Ten milliliters of the seed culture were transferred to $250 \mathrm{ml}$ flasks containing $50 \mathrm{ml}$ of a sterile producing medium consisting of glucose $3.0 \%$, millet steep liquor $1.0 \%$, peptone $1.5 \%, \mathrm{NaCl} 0.5 \%$, and $\mathrm{CaCO}_{3} 0.5 \%$, $\mathrm{pH}$ 7.2. Fermentation was carried out at 210 r.p.m. for $96 \mathrm{~h}$ at $28^{\circ} \mathrm{C}$ on a rotary shaker.

\section{Isolation and purification}

Ten liters of harvest fermentation broth were adjusted to $\mathrm{pH} 3.5$ with oxalic acid and stirred for $30 \mathrm{~min}$. The acidic broth was filtered, adjusted to $\mathrm{pH} 8.0$, and passed through a column of HD-2 $\left(\mathrm{Na}^{+}, 21\right.$; Shanghai Huazhen Sci. \& Tch. Co., Shanghai, China). Active principle adsorbed on the column was eluted 


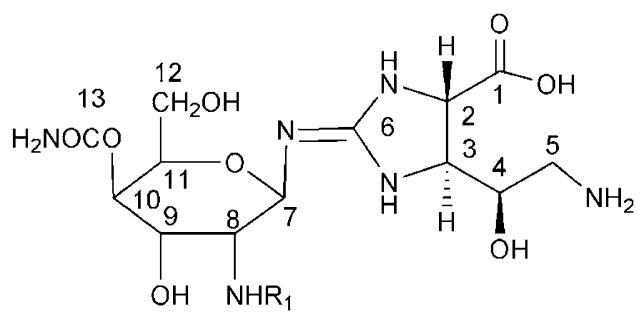

streptothricin acid

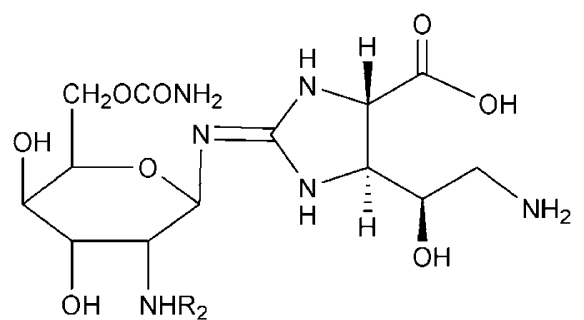

12-carbamoylstreptothricin acid

$\mathbf{1}$ (streptothricin F acid), $\mathrm{R}_{1}=$<smiles>CC(=O)CC(N)C([18O])C[13CH2]N</smiles>

2(streptothricin D acid), $\mathrm{R}_{1}=$

4(12-carbamoylstreptothricin D acid), $R_{2}=$<smiles>CC(=O)CC(N)CCCNC(=O)CC(N)CCCNC(=O)CC(N)CCCN</smiles>

3(12-carbamoylstreptothricin E acid), $\mathrm{R}_{2}=$<smiles>CC(=O)CC(N)CCCNC(=O)CC(N)CCCN</smiles>

5(N-acetyl-streptothricin D acid $), \mathrm{R}_{1}=$<smiles>CC(=O)CC(CCCNC(=O)CC(N)CCCNC(=O)CC(N)CCCN)NC(C)=O</smiles>

Figure 1 Structures of compounds 1-5.

Table 3 Antibacterial in vitro activities of $1-5$ by micro-broth dilution

\begin{tabular}{lcrcrc}
\hline & \multicolumn{5}{c}{$M I C\left(\mu g \cdot \mathrm{ml}^{-1}\right)$} \\
\cline { 2 - 6 } Compounds & $\begin{array}{c}\text { B. subtilis } \\
(1.0088)\end{array}$ & $\begin{array}{c}\text { S. aureus } \\
(1.0089)\end{array}$ & $\begin{array}{c}\text { E. coli } \\
(1.1636)\end{array}$ & $\begin{array}{c}\text { B. cereus } \\
(1.1846)\end{array}$ & $\begin{array}{c}\text { P. aeruginosa } \\
(1.2031)\end{array}$ \\
\hline Streptothricin & 6.3 & 12.5 & 3.1 & 25.0 & 50.0 \\
F & & & & & \\
Streptothricin & 3.1 & 6.3 & 3.1 & 25.0 & 50.0 \\
D & & & & & \\
1 & 25.0 & 50.0 & 50.0 & $>100.0$ & $>100.0$ \\
2 & 12.5 & 25.0 & 12.5 & 25.0 & 50.0 \\
3 & 25.0 & $>100.0$ & 25.0 & 50.0 & $>100.0$ \\
4 & 25.0 & 50 & 12.5 & 50.0 & $>100.0$ \\
5 & 50.0 & $>100.0$ & 50.0 & $>100.0$ & $>100.0$ \\
\hline
\end{tabular}

with $0.5 \mathrm{M} \mathrm{HCl}(81)$. The eluent was adjusted to $\mathrm{pH} 7.0$ with $\mathrm{NaHCO}_{3}$ and concentrated in vacuo to a small volume (about $300 \mathrm{ml}$ ). The concentrated solution was diluted with $\mathrm{MeOH}$ (3:1) to precipitate sodium chloride. The $\mathrm{MeOH}$ was removed on a rotary evaporator, and the aqueous solution was applied on a column of CM-Sephadex C- $25\left(0.51, \mathrm{Na}^{+}\right)$. The column was eluted with a linear gradient of water and $1.0 \mathrm{M} \mathrm{NaCl}$ solution (11 each). The eluents were collected in $50 \mathrm{ml}$ fractions and analyzed by HPLC-MS/MS. The analyses were performed on a Finnigan LCQ Advantage MAX LC/MS (Thermo Finnigan, San Jose, CA, USA) equipped with a Waters (Waters, Milford, MA, USA) Atlantis dC18 column $(4.6 \times 250 \mathrm{~mm}, 5 \mu \mathrm{m})$, and a water/TFA/acetonitrile gradient was used as mobile phase. The gradient started with $5 \%$ acetonitrile in $0.1 \%$ aqueous TFA for $10 \mathrm{~min}$. The percent of acetonitrile was increased to $20 \%$ in the next $10 \mathrm{~min}$. The flow rate of the mobile phase was $0.8 \mathrm{ml} \mathrm{min}^{-1}$ and the injection volume of sample was $10 \mu \mathrm{l}$. The eluate from the HPLC was introduced into a splitter to provide a $0.1 \mathrm{ml} \mathrm{min}^{-1}$ flow into the mass spectrometer. An electrospray ionization (ESI) interface with positive-ion mode was used. The ESI conditions were as follows: source voltage $4.5 \mathrm{kV}$, capillary temperature $300^{\circ} \mathrm{C}$, sheath gas flow 75 , auxiliary gas flow 10 , capillary voltage $10 \mathrm{~V}$. A data-dependent acquisition was used in the LC-MS/MS experiments. The collision energy for MS/MS was adjusted to $35 \%$ and the isolation width of precursor ions was 3.0 mass units. The results showed that ST acids were distributed in fractions $25-28$ and $72-77$, and these fractions were combined with fractions A and B, respectively. The two fractions were further desalted by chromatography on active carbon columns and concentrated under reduced pressure to a small volume (about $10 \mathrm{ml}$ ). The concentrated fractions were further separated on a Shimadzu (Tokyo, Japan) 6AD HPLC apparatus equipped with a column of Hypersil ODS-BP $(20 \times 250 \mathrm{~mm}, 10 \mu \mathrm{m}$, flow rate $3.5 \mathrm{ml} \mathrm{min}^{-1}$ ), monitored by a Shodex (Kawasaki, Japan) RI-101 detector. Fraction A was eluted with $6.0 \% \mathrm{MeOH}$ containing 2.0\% TFA; fraction B was eluted with $8.0 \% \mathrm{MeOH}$ containing $6.0 \%$ TFA. Five fractions were collected according to the peaks in the HPLC profiles, and each fraction was lyophilized, redissolved in water and passed through a column packed with 717 anion ion exchange resin $\left(\mathrm{Cl}^{-}, 50 \mathrm{ml}\right.$; Shanghai Huazhen Sci. \& Tch. Co.) to exchange TFA for chloride. The solutions were lyophilized to yield five compounds, with $\mathbf{1}(45 \mathrm{mg}), \mathbf{2}(83 \mathrm{mg})$ and $\mathbf{3}(51 \mathrm{mg})$ being from fraction $\mathrm{A}$, and $\mathbf{4}(32 \mathrm{mg})$ and 5 (36 $\mathrm{mg})$ being from fraction $\mathrm{B}$, respectively.

\section{Structure elucidation}

The structures of these compounds were elucidated on the basis of extensive 1D and 2D NMR experiments and high-resolution mass spectrometry, and confirmed by comparison of their ESI-MS/MS data with those of LC-MS/MS. Melting points were measured on an X4 apparatus and uncorrected. IR spectra 
were determined on an IR-450 instrument (KBr plate). ${ }^{1} \mathrm{H},{ }^{13} \mathrm{C}$ NMR, DEPT, COSY, heteronuclear single quantum coherence and $\mathrm{HMBC}$ spectra were taken on a Bruker Avance $500 \mathrm{MHz}\left(500 \mathrm{MHz}\right.$ for ${ }^{1} \mathrm{H}$ and $125 \mathrm{MHz}$ for ${ }^{13} \mathrm{C}$, respectively) spectrometer (Bruker Biospin $\mathrm{GmbH}$, Rheinstetten, Germany) in $\mathrm{D}_{2} \mathrm{O}$ solution with TMS as an internal standard. The ESI-MS/ MS and HR-ESI-MS spectra were obtained on a Finnigan LCQ LC-MS ${ }^{\text {n }}$ (Thermo Finnigan) and a Bruker APEX II mass spectrometer (Bruker Biospin $\mathrm{GmbH}$ ) using glycerol as the matrix. Optical rotation was measured in methanol solution on a Perkin-Elmer 341 Polarimeter (Perkin Elmer, Fremont, CA, USA).

\section{Antibacterial assay}

Minimum inhibitory concentration of compounds 1-5 against $B$. subtilis, S. aureus, E. coli, B. cereus and P. aeruginosa were tested by the micro-broth dilution method. ${ }^{16}$ The inoculum was prepared by suspending several colonies from an overnight culture of tested bacteria from 5\% sheep blood agar medium in Mueller-Hinton broth, and adjusting to a 0.5 McFarland standard (approximately $1.5 \times 10^{8} \mathrm{cells} \mathrm{m}^{-1}$ ). A further dilution of 1:200 was made by placing $0.25 \mathrm{ml}$ of the adjusted suspension into $49.75 \mathrm{ml}$ of Mueller-Hinton broth. Stock solutions of tested compounds and streptomycin (positive control) in sterile water were prepared at a concentration of $1000 \mu \mathrm{g} \mathrm{ml}^{-1}$ and used immediately or stored in working samples at $-20^{\circ} \mathrm{C}$ until used. Doubling dilutions of the tested compounds were prepared in Mueller-Hinton broth. All antimicrobial solutions were prepared in large volumes $(50 \mathrm{ml}) ; 0.1 \mathrm{ml}$ samples of the antibiotic solutions and $0.1 \mathrm{ml}$ inoculated suspension of the test bacterium were delivered to wells of a 96-well plate. The final concentration of inoculum in each well was $3.7 \times 10^{5} \mathrm{cells}^{-1}$. Minimum inhibitory concentration end points were read after $18 \mathrm{~h}$ of incubation at $35^{\circ} \mathrm{C}$, and were defined as the lowest concentration of antibiotics that resulted in no bacterial growth as indicated by the ODs at $650 \mathrm{~nm}$. The blank control tube contained only bacteria. Three replications were carried out for each sample.

\section{ACKNOWLEDGEMENTS}

This work was supported by the National Key Project for Basic Research of China (No. 2003CB114404) and the Hi-Tech Research and Development Project of China (No. 2002AA2455121). We thank Xi'an Modern Chemistry Research Institute for NMR analysis.
1 Waksman, S. A. \& Woodruff, H. B. Streptothricin, a new selective bacteriostatic and bactericidal agent particularly against Gram-negative bacteria. Proc. Soc. Exptl. Biol. Med. 49, 207-209 (1942).

2 Khokhlov, A. S. Achievements in the study of streptothricin antibiotics. Antibiotiki. 28, 613-622 (1983).

3 Kim, B. T. et al. N-methylstreptothricin D, a new streptothricin-group antibiotic from a Streptomyces spp. J. Antibiot. 47, 1333-1336 (1994).

4 Ando, T. et al. New streptothricin-group antibiotics, AN-201 I, II and III. J. Antibiot. 40, 1140-1145 (1987).

5 Goo, Y. M. et al. A new streptothricin family antibiotic producing Streptomyces spp. SNUS 8810-111: characterization of the producing organisms, fermentation, isolation, and structure elucidation of antibiotics. Arch. Pharm. Res. 19, 153-159 (1996).

6 Hamano, Y., Matsuura, N. \& Kitamura, M. A novel enzyme conferring streptothricin resistance alters the toxicity of streptothricin $D$ from broad-spectrum to bacteriaspecific. J. Biol. Chem. 281, 16842-16848 (2006).

7 Inamori, Y., Tominaga, H., Okuno, M., Sato, H. \& Tsujibo, H. Antimicrobial activity on plant-pathogenic microorganisms and phytogrowth-inhibitory activity of streptothricin antibiotics, racemomycin-A and -C. Chem. Pharm. Bull. 36, 1577-1580 (1988).

8 Taniyama, H., Sawada, Y. \& Kitagawa, T. Studies on the inactivation and regeneration of streptothricin. J. Antibiot. 24, 662-666 (1971).

9 Ji, Z. Q., Wang, M. A., Zhang, J. W., Wei, S. P. \& Wu, W. J. Two new members of streptothricin class antibiotics from Streptomyces qinlingensis sp. nov. J. Antibiot. 60, 739-744 (2007).

10 Ji, Z. Q., Zhang, J. W., Wei, S. P., Wu, W. J. \& Wang, M. A. Identification of streptothricin class antibiotics in the early-stage of antibiotics screening by electrospray ionization mass spectrometry. J. Antibiot. 81, 660-667 (2008).

11 Hisamoto, M. et al. A-53930A and B, novel N-type $\mathrm{Ca}^{2+}$ channel Blockers. J. Antibiot. 51, 607-617 (1998)

12 Sawada, Y., Sakamoto, H. \& Taniyama, H. Studies on chemical modification of streptothricin-group antibiotics. III. Pritial N-acetylation of racemomycins and their biological activity. Yakugaku Zasshi. 94, 176-180 (1974).

13 Sawada, Y. \& Taniyama, H. Studies on chemical modification of streptothricin-group antibiotics. IV. Preparation of $\beta$-N-acetyl-racemomycin-A and its antimicrobial activity. Yakugaku Zasshi. 94, 264-266 (1974)

14 Kusumoto, S., Kambayashi, S., Imaoka, S., Shima, K. \& Shiba, T. Total chemical structure of streptothricin. J. Antibiot. 35, 925-927 (1982).

15 Hamano, Y., Maruyama, C. \& Kimoto, H. Construction of a knockout mutant of the streptothricin-resistance gene in Streptomyces albulus by electroporation. Actinomycetologica. 20, 35-41 (2006).

16 Martha, M. T., David, F. W. \& Melvin, I. M. Antimicrobial susceptibility testing of Streptococcus pneumoniae by micro-broth dilution. Antimicrob. Agents. Chemother. 18, 579-581 (1980). 